International Journal of Current Advanced Research

ISSN: O: 2319-6475, ISSN: P: 2319 - 6505, Impact Factor: SJIF: 5.995

Available Online at www.journalijcar.org

Volume 6; Issue 4; April 2017; Page No. 3297-3299

DOI: http://dx.doi.org/10.24327/ijcar.2017.3299.0254

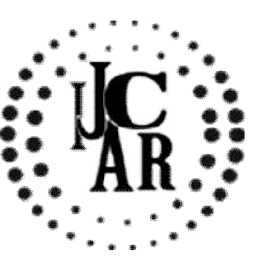

Research Article

\title{
KNOWLEDGE, ATTITUDE, PRACTICE ABOUT CONSCIOUS SEDATION IN ADULTS AMONG DENTAL PRACTITIONERS -A QUESTIONNAIRE BASED STUDY
}

\author{
Karthiga Devi G., Dhanraj.M., Anandhi.T
}

Saveetha Dental College Chennai-77

\begin{tabular}{l}
\hline A R T I C L E I N F O \\
\hline Article History: \\
Received $12^{\text {th }}$ January, 2017 \\
Received in revised form $5^{\text {th }}$ February, 2017 \\
Accepted $22^{\text {nd }}$ March, 2017 \\
Published online $28^{\text {th }}$ April, 2017
\end{tabular}

Key words:

Conscious SEDATION, adults, anxiety, dental pain control

\begin{abstract}
A B S T R A C T
Background: Conscious sedation is a combination of medicines to help as relax (a sedative) and to block pain (an anesthetic) during a medical or dental procedure. The patient will probably stay awake but may not be able to speak.Anxiety and fear in relation to dentistry are long-standing problems and the incidence of dental fear does not appear to be decreasing. It can result in poor dental health and wastage of clinical time. Conscious sedation is one method of allaying anxiety in dental patients and enables such patients to accept dental treatment.

Aim and Objectives: to assess the levels of dental anxiety in these adults, the impact on their attendance for dental treatment, and their knowledge of and desire to have conscious sedation, should it be available.

Methods and Materials: 100 Dental practitioners from chennai participated in this survey. The questionnaire included 15 questions and the participants responded to the all questions in the questionnaire and there were no dropouts in the study. The data was extracted and analysed.

Results and Conclusion: This study concluded $83 \%$ of practitioners had referred patients for sedation. With the reduction in the provision of general anaesthesia, there is a need to train more practitioners to undertake conscious sedation in primary care.
\end{abstract}

Copyright $(2017$ Karthiga Devi G., Dhanraj.M., Anandhi.T . This is an open access article distributed under the Creative Commons Attribution License, which permits unrestricted use, distribution, and reproduction in any medium, provided the original work is properly cited.

\section{INTRODUCTION}

Conscious sedation is a combination of medicines to help as relax (a sedative) and to block pain (an anesthetic) during a medical or dental procedure. The patient will probably stay awake but may not be able to speak ${ }^{1}$. Anxiety and fear in relation to dentistry are long-standing problems and the incidence of dental fear does not appear to be decreasing. It can result in poor dental health and wastage of clinical time ${ }^{2}$. Conscious sedation is one method of allaying anxiety in dental patients and enables such patients to accept dental treatment ${ }^{3}$. Dental anxiety remains a significant barrier to care for many patientsand conscious sedation via oral, intravenous and inhalational routes has been shown to be a safe alternative to general anaesthesia in many cases ${ }^{4}$. Whatever the sedation method used, it is of fundamental importance that the level of sedation must be such that the patient remains conscious and is able to both understand and respond to verbal commands during the entire sedation treatment session ${ }^{5}$. Where patients are unable to communicate verbally in their normal, presedated state (for example, deaf patients who use sign language to communicate); then their usual method of

*Corresponding author: Karthiga Devi G Saveetha Dental College Chennai-77 communication must be maintained throughout the entire sedation treatment session, from first administering the sedation agent through to patient discharge ${ }^{6}$. Its aims are to assess the levels of dental anxiety in these adults, the impact on their attendance for dental treatment, and their knowledge of and desire to have conscious sedation, should it be available ${ }^{7}$.

\section{METHODS AND MATERIALS}

100 Dental practitioners from chennai participated in this survey. The questionnaire included 15 questions and the participants responded to the all questions in the questionnaire and there were no dropouts in the study. The data was extracted and analysed.

\section{This questionnaire identified as}

\section{Practitioners Detail}

1. Gender

2. Year of qualification

3. Postcode of practice

4. Sector of practice

5. Generalist or specialist

6. whether SEDATION was offered 
IF YES,

Types of patient treated

Routes of administration

Sedative agents used

Training received for SEDATION

Details of the team undertaking sedation

Have you experienced any complications while handling those patients?

Has patients recovered from these cases?

If No,

why you don't prefer SEDATION?

Are you willing to receive training for SEDATION?

Space was also left for specific comments.

\section{Questionnaire}

The questionnaire was conducted based upon theirknowledge, attitude, practice about conscious sedation in adults among Dental practitioners. This questionnaire was divided into 3 parts. The first part consist of the Dental practitioners general information which included their gender, year of qualification, postcode of practice, sector of practice, Generalist or specialist etc,. It help in finding of their praction level based on their personal data. The second partconsist of question based on whether sedation was offered or not. It includes the Types of patients treated, routes of administration, sedative agents used, training used for sedation etc,.The final part consist of not offering sedation it includes why they don't prefer sedation and whether they were willing to receive training for sedation. After completion by the questionnaire, the responses were scored and interpreted in accordance with the norms.

\section{RESULTS}

For the above study it was concluded that all respondents had a knowledge about conscious sedation. The year of qualification for all responding dentists offering sedation is detailed in Table 1.

Table 1 Year of qualification for all responding dentist

\begin{tabular}{cccccc}
\hline $\begin{array}{c}\text { Year } \\
\text { qualified }\end{array}$ & $>\mathbf{5}$ & $\mathbf{5 - 3 y r s}$ & $<\mathbf{3}$ & $\begin{array}{c}\text { No } \\
\text { reply }\end{array}$ & Total \\
\hline Dentists & 20 & 26 & 54 & 0 & 100 \\
\hline
\end{tabular}

In total 100 dentists offered some form of sedation; almost two thirds of them $(\mathrm{n}=73,73 \%)$ were in the urban , 27 $(27.6 \%)$ semi urban and six $(6.9 \%)$ in both urban and semi urban is detailed in table 2 .

Table 2 sector of dental practice

\begin{tabular}{ccccc}
\hline Location & Urban & Semi urban & Rural & Total \\
\hline $\mathrm{N}(\%)$ & 73 & 27 & 0 & 100 \\
\hline
\end{tabular}

Table 3 details the route of sedation used adults and by dentists who offered it.For adults just over half $(\mathrm{n}=71,71 \%)$ of dentists offered IV, with $23(23.7 \%)$ and $6(6.4 \%)$ offering oral and both IV and oral respectively.

Table 3 Route of SEDATION offered by dentist for adults

\begin{tabular}{cc}
\hline Route of Sedation offered by dentists & For adults \\
\hline Intravenous & 71 \\
Oral & 23 \\
Intravenous and oral & 6 \\
Total & 100 \\
\hline
\end{tabular}

Reasons for this variation are not clear, but might include the undergraduate and postgraduate training, differences in dental school curricula, availability of training courses in the area and patient choice. The estimated travelling times reported to sedation centres in this study are good, with over half of journeys estimated to be less than 30 minute.

Table 4 sedation training undertaken by dentist

\begin{tabular}{cccc}
\hline S.no & $\begin{array}{c}\text { Type of } \\
\text { training }\end{array}$ & $\begin{array}{c}\text { Dentist offering } \\
\text { Sedation }\end{array}$ & $\begin{array}{c}\text { Dentist not offering } \\
\text { Sedation }\end{array}$ \\
\hline 1$)$ & Undergraduate & 43 & 9 \\
$2)$ & Postgraduate & 40 & 8 \\
& Total & 83 & 17 \\
\hline
\end{tabular}

adults

E

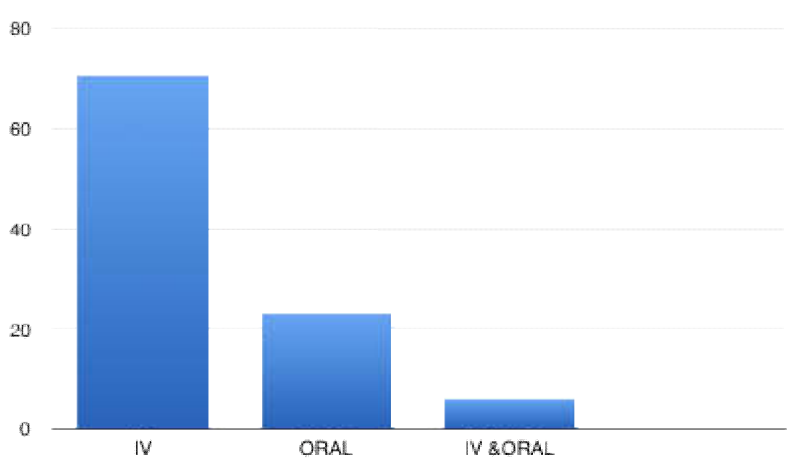

Graph 1 Type of sedation offered in dental practice

\section{DISCUSSION}

Despite the publication of a number of authoritative guidelines on pain and anxiety control for dentistry it has become evident that there remain areas of confusion and lack of consensus ${ }^{8}$. Competently provided Conscious Sedation is safe, valuable and effective. It is absolutely essential that a wide margin of safety be maintained between Conscious Sedation and the unconscious state of general anaesthesia. Conscious Sedation must under no circumstances be interpreted as light general anaesthesia ${ }^{9}$. Operating chairs and patient trolleys must be capable of being placed in the headdown tilt position ${ }^{10}$. All equipment for the administration of intravenous sedation must be available in the treatment area and appropriately maintained. Supplemental oxygen delivered under intermittent positive pressure must be immediately available $^{11}$.

Fasting for Conscious Sedation is not normally required however some authorities recommend the same fasting requirements as for general anaesthesia ${ }^{12}$.The three standard techniques of inhalation, oral and intravenous sedation employed in dentistry are effective and adequate for the vast majority of patients. The simplest technique to match the requirements should be used. The generally agreed standard technique for intravenous sedation is the use of a titrated dose of a single benzodiazepine ${ }^{13}$. Conscious Sedation for children must only be undertaken by teams which have adequate training and experience. Nitrous oxide / oxygen should be the first choice for paediatric dental patients. Intravenous sedation for children is rarely appropriate ${ }^{14}$. Recovery from sedation is a progressive step-down from completion of treatment through to discharge. A member of the dental team must supervise and monitor the patient throughout this period. The decision to discharge a patient into the care of the escort 
following any type of sedation must be the responsibility of the sedationist ${ }^{15}$.

The majority of respondents gave the postcode of their practices on the questionnaire. By using this information from respondents that currently offer sedation, the availability of primary care practitioners offering sedation can be deduced. In addition, where sedation is being used instead of a general anaesthetic in the past there is another dimension to consider. A general anaesthetic required one visit to complete all treatment, often with restorable teeth being extracted in a single visit. Sedation involves more than one visit where multiple quadrant extractions or restorations were also involved. It is not unusual for patients to need four or more appointments ${ }^{16}$.

The data show wide variation in the availability of primary dental care sedationists; not all areas with a high dentist to population ratio have access to a primary care sedationist, while some areas with generally poor dentist to population ratios have relatively high numbers of sedationists.

\section{CONCLUSION}

This study concluded $83 \%$ of practitioners had referred patients for sedation. With the reduction in the provision of general anaesthesia, there is a need to train more practitioners to undertake conscious sedation in primary care

\section{Reference}

1. Kelly M et al. Adult Dental Health Survey. Oral Health in the United Kingdom in 1998. London: The Stationary Office, 2000.

2. Crawford A N. The use of nitrous oxide-oxygen inhalation sedation with local anaesthesia as an alternative to general anaesthesia for dental extractions in children. Br Dent $J$ 1990; 168: 395-398.

3. Kaufman E, Jastak J T. Sedation for outpatient procedures. Compend Cont Educ Dent 1995; 16: 462480.

4. Blain K M, Hill F J. The use of inhalational sedation and local anaesthesia as an alternative to general anaesthesia for dental extractions in children. Br Dent $J$ 1998; 184: 608-611.
5. Wilson K E, Girdler N M, Welbury R R. Randomized, controlled, cross-over clinical trial comparing intravenous midazolam sedation with nitrous oxide sedation in children undergoing dental extractions. $\mathrm{Br} J$ Anaesth 2003; 91: 850-856.

6. Wilson K E, Girdler N M, Welbury R R. Randomized, controlled, cross-over clinical trial comparing intravenous midazolam sedation with nitrous oxide sedation in children undergoing dental extractions. $\mathrm{Br} J$ Anaesth 2003; 91: 850-856.

7. Whiston S, Prendergast M J, Williams S A. Sedation in primary dental care: an investigation in two districts of Northern England. Br Dent J 1998; 184: 390-393.

8. Academy of Medical Royal Colleges and their Faculties. Implementing and ensuring safe Sedation Practice for healthcare procedures in adults. Academy of Medical Royal Colleges. November 2001

9. Standards for Conscious Sedation. Report of an independent expert working group convened by the Society for the Advancement of Anaesthesia in dentistry. October 2000.

10. Report of the Joint Faculties Working Party on Sedation .Faculties of Dental Surgery and General Dental Practitioners. Royal College of Surgeons of England, London. 1996.

11. Sedation in Dentistry. Undergraduate Training. Dental Sedation Teachers Group. May 1999

12. The 2000 Resuscitation Guidelines for Use in the United Kingdom: Resuscitation Council (UK).

13. Medical gas cylinders, valves and yoke connections BS EN 8501997 British Standards Institute

14. Conscious sedation. A referral guide for dental practitioners. Society for the Advancement of Anaesthesia in Dentistry (SAAD) and Dental Sedation Teachers Group (DSTG). September 2001

15. Witcher CE, Zimmerman DC, Tonn EM, Piziali RL. Control of occupational exposure in the dental operatory. JADA, 1977, 95: 763-776

16. Monitoring of Patients During Dental Anaesthesia or Sedation, Association of Dental Anaesthetists, 1990.

\section{How to cite this article:}

Karthiga Devi G (2017) ' Knowledge, Attitude, Practice About Conscious Sedation In Adults Among Dental Practitioners -A Questionnaire Based Study', International Journal of Current Advanced Research, 06(04), pp. 3297-3299.

DOI: http://dx.doi.org/10.24327/ijcar.2017.3299.0254 